Research Article

\title{
2D Semimodel of Full-Section Anchorage in Thick Soft Rock Roadway
}

\author{
Xianzhou Lyu $\left(\mathbb{D},{ }^{1}\right.$ Zenghui Zhao $\mathbb{D}^{2,3}$ Qing Ma, ${ }^{2,3}$ Xiaojie Wang, ${ }^{1}$ and Xiaojie Gao ${ }^{2,3}$ \\ ${ }^{1}$ College of Architecture and Civil Engineering, Shandong University of Science and Technology, Qingdao 266590, China \\ ${ }^{2}$ State Key Laboratory of Mining Disaster Prevention and Control Co-founded by Shandong Province and the Ministry of Science \\ and Technology, Qingdao 266590, China \\ ${ }^{3}$ College of Mining and Safety Engineering, Shandong University of Science and Technology, Qingdao 266590, China
}

Correspondence should be addressed to Zenghui Zhao; tgzyzzh@163.com

Received 11 April 2018; Accepted 16 August 2018; Published 23 September 2018

Academic Editor: Hamid Toopchi-Nezhad

Copyright (C) 2018 Xianzhou Lyu et al. This is an open access article distributed under the Creative Commons Attribution License, which permits unrestricted use, distribution, and reproduction in any medium, provided the original work is properly cited.

\begin{abstract}
This paper focuses on the reinforcement effect of full-face anchorage in thick soft rock roadway. A 2D semimodel of full-face anchorage in roadway with thick surrounding soft rock was proposed firstly by transforming the confinement effect of the excavation face in the longitudinal direction as the virtual internal support force at the circumferential surface. Then, based on the theory of elasticity, the theoretical model of the coupling effect between surrounding rock and anchoring system was established, and the analytical solutions of stress and displacement were obtained employing superposition principle. Finally, the theoretical solution was verified by numerical simulation, and the distribution laws of stress release-anchor stock-surrounding rock coupling were analyzed in detail considering stress release. Results demonstrated that the stress field of the surrounding rock diverse widely with different stress release coefficients. With the increasing of stress release coefficient, the radial stress of the surrounding rock decreases, while the tangential stress increases. The supporting role of the bolt is mainly reflected in improving the radial stress of the anchorage zone. However, it has little effect on the tangential stress. What is more, the anchoring effect is more significant to soft rock stress than hard rock. In addition, the prestress of rock bolt has a certain matching relation with the bolt parameters, the surrounding rock parameters, and the initial stress. This study laid a theoretical foundation for further analysis of the interaction between surrounding rock and bolt supporting in plastic zone.
\end{abstract}

\section{Introduction}

The Jurassic and Cretaceous weakly cemented soft rocks widely exist in western China. Due to the special diagenetic environment and occurrence conditions, unique physical and mechanical properties are formed, which are characterized by low strength and poor cementation and easy to mud and disintegrate. After excavation, the surrounding rock only has a short period of self-stabilization, which can easily lead to engineering accidents or disasters such as surface subsidence, ground cracking, landslide, big fall roof, serious floor heave. So, it brings great hidden trouble to the energy development, geotechnical engineering construction, and environmental management in Western China [1-3]. Thus, the urgent problem is to put forward the effective reinforcement measures for various weakly cemented soft rock engineering constructions, especially to reveal the reinforcement mechanism, so as to ensure the safe operation of projects in western China.

Mine roadways in western China is mostly located in thick weakly cemented rock strata. Because the primary fissure or joint of rock mass is not developed, the slurry is difficult to inject and infiltrate into the rock mass, resulting in poor reinforcement effect of grouting. Therefore, the fullface anchorage support method is widely adopted in the thick weakly cemented soft rock roadways $[4,5]$. However, along with the roadway working face moving forward, how to make the initial state of rock mass without major disturbance and to keep the surrounding rock in a relatively stable state is still a very complicated issue. It involves the selection of the way of roadway excavation, the use of the space effect of the excavation surface, and the determination 
of the best support type, support parameters, and support timing and many other aspects [6-10]. Therefore, it is necessary to make full use of the space constraints effect of roadway excavation face on the deformation of the roadway wall, timely installing the anchoring structure. The process of the continual advancing of the roadway is also the process of gradual unloading of surrounding rock in the subsequent excavation, and the magnitude of unloading and the mechanical response resulting from the process is also extremely complicated. The excavation of the underground cavern is almost equivalent to the removal of internal constraints, which will cause the stress change of the medium around the excavation area, resulting in more complex stress release [11-14]. At present, the theoretical analysis for stress release rate of roadway excavation is not yet mature. Some scholars have made some researches based on experimental methods and numerical simulation methods. In the experimental aspect, such as large scale 3D geomechanical model test, the load release process of surrounding rock during excavation is studied, and the characteristics and the differences of load release process of surrounding rock under different construction methods are revealed [15-17]. Through the on-site monitoring data, the variation regularity of surrounding rock-support contact pressure during the stress release process and its spatial distribution characteristics of the roadway are analyzed $[18,19]$. The research results show that the release of excavation stress is related to the characteristics of rock and soil layer, the construction method, the advancing of excavation face, and the conditions of subsequent lining construction. However, although the experimental study can get the load-sharing ratio of the supporting structure, it is difficult to monitor the stress release process in front of the excavation face, so the stress release rate in the excavation process cannot be determined. The true three-dimensional calculation model can be adopted in numerical simulation to simulate complex surrounding rock characteristics and construction conditions, so we can obtain good effect when considering the space-time constraint effect of surrounding rock. Among them, the numerical simulation of roadway based on engineering experience and the research on the deformation law of roadway surrounding rock and structure under different stress release rates are more common. In the numerical simulation, the influence of different stress release rates on the roadway excavation or the hypothesis of the assumed stress release rate is mostly studied. At present, most of the researches focus on the threedimensional simulation of the roadway construction process, analyze the stress and deformation law of surrounding rock and lining with construction, or through the numerical model to analyze the change of the radial virtual support force of the excavation surface based on the radial displacement release coefficient of roadway wall [20-23]. Some scholars also put forward some calculation methods of stress release rate through numerical simulation, such as solving the stress release rate through the volume loss rate [24] and solving the stress release rate through the displacement release rate [25]. However, the use of a true three-dimensional computational model to simulate the above-mentioned complex surrounding rock features and construction conditions is needed, but difficult to achieve, and its expensive calculation cost and limited computer memory are very troublesome. Therefore, some researchers established a two-dimensional model of roadway under certain conditions and resimulation of excavation by stress release rate control [26, 27]. However, this simplified analysis methods must satisfy that the axial direction of the roadway which is one of the main stress directions. Therefore, it is generally accepted that the three-dimensional problem of roadway excavation is assumed to be a two-dimensional plane strain problem. Especially when the problem of three-dimensional excavation is equivalent to a plane problem, it is still a work of practical value.

Stated thus, the common considerations of the above works are to determine the impact of the excavation load on the excavation domain and the contribution to the pressure of the support structure. Most of the research results focus on the variation rule of the contact pressure in the process of stress release in roadway engineering and the contact pressure between surrounding rock and lining. Few studies have been done on the full-face anchoring effect of surrounding rock in weakly cemented soft rock roadway with excavation disturbance. In particular, the research on the mechanical response of surrounding rock-blot support system with different stress release has rarely been reported. For this reason, in view of the full-section anchoring support problem in weakly cemented soft rock roadways, a $2 \mathrm{D}$ semimodel of full-section anchorage in roadway with thick surrounding soft rock was proposed firstly. Then, based on the theory of elasticity, the theoretical model of the coupling effect between surrounding rock and anchoring system was established. Finally, the theoretical solution was verified by numerical simulation, and the distribution laws of stress release-anchor stock-surrounding rock coupling were analyzed in detail considering stress release. Our research results will provide a theoretical basis for the stability control of roadways in coal mines by the explanation of the interaction mechanism of stress release-rock bolt-surrounding rock system.

\section{2D Semimodel for Full-Face Anchorage of Roadways}

As is well known, the excavation of underground tunnels and mine roadways is a gradual process, which is a typical three-dimensional problem. If the time effect caused by the different excavation and support time been factored in, it will become a more complex four-dimensional problem. Convergence-constraint method considered the gradual and three-dimensional features of roadway tunneling. Based on this, we can characterize the three-dimensional effect by the investigation of the constraint release effect on the certain roadway section in the process of continuous propulsion.

As shown in Figure 1, the curve of the distance of the radial deformation to the excavation face is in the shape of a semicircular dome; that is, the spatial geometric effect of 


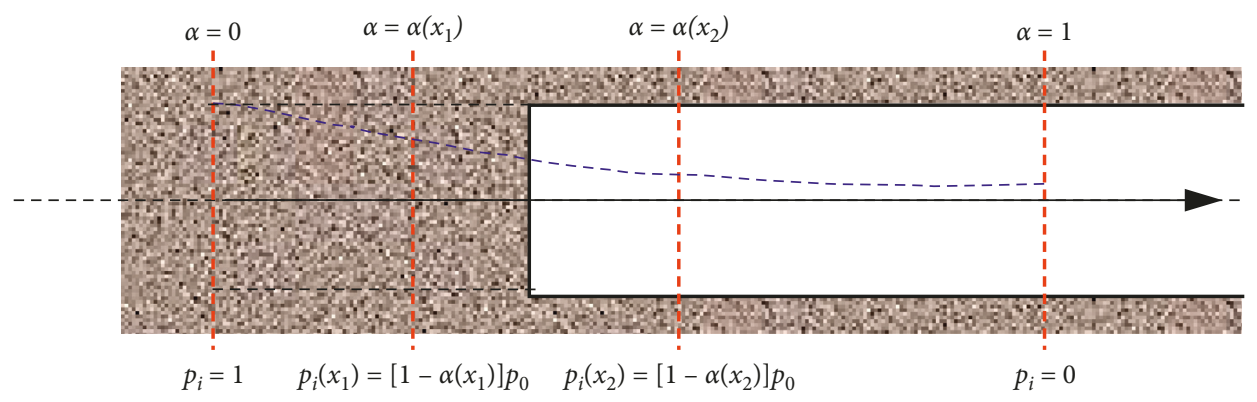

FIGURE 1: Space constraint effects of working force on different sections.

roadway excavation face shows as a semicircular dome constraint along the longitudinal axis of the roadway, and the one in the transverse direction of the roadway shows as a ring constraint. The coupling effects of the above two constraints make the surrounding rock near the excavation face maintain relative stability in a certain time without support. The rock constraint effect around the heading face on the specific section is constantly changing with the change of the distance between them. This constraint effect can limit the convergence of surrounding rock deformation and also control the stress release of surrounding rock, while the stress release process will cause the mechanical properties deterioration of the surrounding rock. Panet and Guenot [28] introduced the concept of stress release coefficients to characterize the loss of this constraint effect. If the supporting effect is not considered, the circular constraint effect of the excavation face can be described as the virtual support force $\left(p_{i}\right)$ in the longitudinal section direction, that is,

$$
p_{i}(x)=[1-\alpha(x)] p_{0},
$$

where $x$ is the axial direction of the roadway, $\alpha$ is stress release coefficient. Obviously, $\alpha$ is the function of $x$ which scale is $0 \leq \alpha \leq 1$. The undisturbed location away from the roadway face, $\alpha=0, p_{i}=p_{0}$. At the far right behind the heading face, the constraint effect will disappear, $\alpha=1$, $p_{i}=0$. For the sections $x=x_{1}$ and $x=x_{2}$, the virtual internal pressure will increase and decrease with the heading face advancing.

Brady and Brown [29] assumed the formation as an elastic medium and obtained the expressions of different stress release coefficients by elastic stress analysis method. The results show that if the $3 \mathrm{D}$ problem described in the process of excavation face advancing is transformed into a $2 \mathrm{D}$ problem, it must satisfy that (1) the roadway axis is one of the principal stress direction and (2) the geological conditions remain unchanged along the axial direction of the roadway.

In this paper, the initial ground stress field of the weakly cemented soft rock roadway is mainly subject to the gravity stress of rock mass, so the first condition is easy to meet. Because the weakly cemented soft rock layer is thicker, the latter condition can also be met by setting the lithology of the axial direction of the excavated roadway as piecewise homogenization. Therefore, the constraint effect of the excavation face in the longitudinal direction can be equivalent to the virtual inner support force at the circumferential face, so as to maintain the main characteristics of the original 3D problem, namely, the spatial effect. So, we can discuss the influence of the constraint effect on the supporting effect of arbitrary section under $2 \mathrm{D}$ plane strain condition. The equivalent model of one dimension reduction can be called a $2 \mathrm{D}$ semianalysis model. It is well accepted that the results obtained from the $2 \mathrm{D}$ model can be basically consistent with the $3 \mathrm{D}$ calculation.

Figure 2 shows the 2D semianalysis model for the fullface anchorage of the weakly cemented soft rock roadway. In the physical sense, it is more reasonable to regard the constraint effect of the heading face to be the virtual support of the roadway. The existence of the heading face only affects the surrounding rock in a limited area. So, the constraints of the end face can be equivalent to the support force attached to the boundary according to the Saint Venant principle. In order to get a closed solution for the full-face anchorage, we let the surrounding rock be in hydrostatic state. In Figure 2, $p_{0}$ is the initial stress and can be calculated by $p_{0}=\gamma h$ where $\gamma$ is bulk density of overlying strata, and $h$ is the buried depth. $p_{i}(x)$ is the virtual internal support force at $\mathrm{X}$ cross section and $\alpha(x)$ is the stress release coefficient, which decreases as the distance from the excavation face increases.

\section{Theoretical Analysis of Roadway with Full-Face Anchorage}

3.1. Theoretical Model. Let the row and line space of rock bolts supporting to be $n_{\mathrm{c}}$ and $n_{\mathrm{a}}$, the length is $L$, the diameter is $a$, and the radius of the roadway is $R$. The elastic modulus of the rock mass is $E$, Poisson's ratio is $v$, and the elastic modulus of the rock bolt is $E_{\mathrm{b}}$. Choose a specific section, when the stress release coefficient $\alpha=\alpha^{*}$, this section begins to install rock bolts, at this time, the virtual internal pressure of the roadway wall is $p^{*}$. In order to deduce the analytical solution of the problem, the following assumptions are made:

(1) Assuming that the bolt is evenly installed around the surface of the roadway

(2) The influence range of the reinforcement area of each bolt is $n_{\mathrm{c}} \times n_{\mathrm{a}}$, without cross effect between adjacent bolts

Based on the above hypothesis, the axial load of the roadway will be symmetrical along the central axis, so the $3 \mathrm{D}$ 

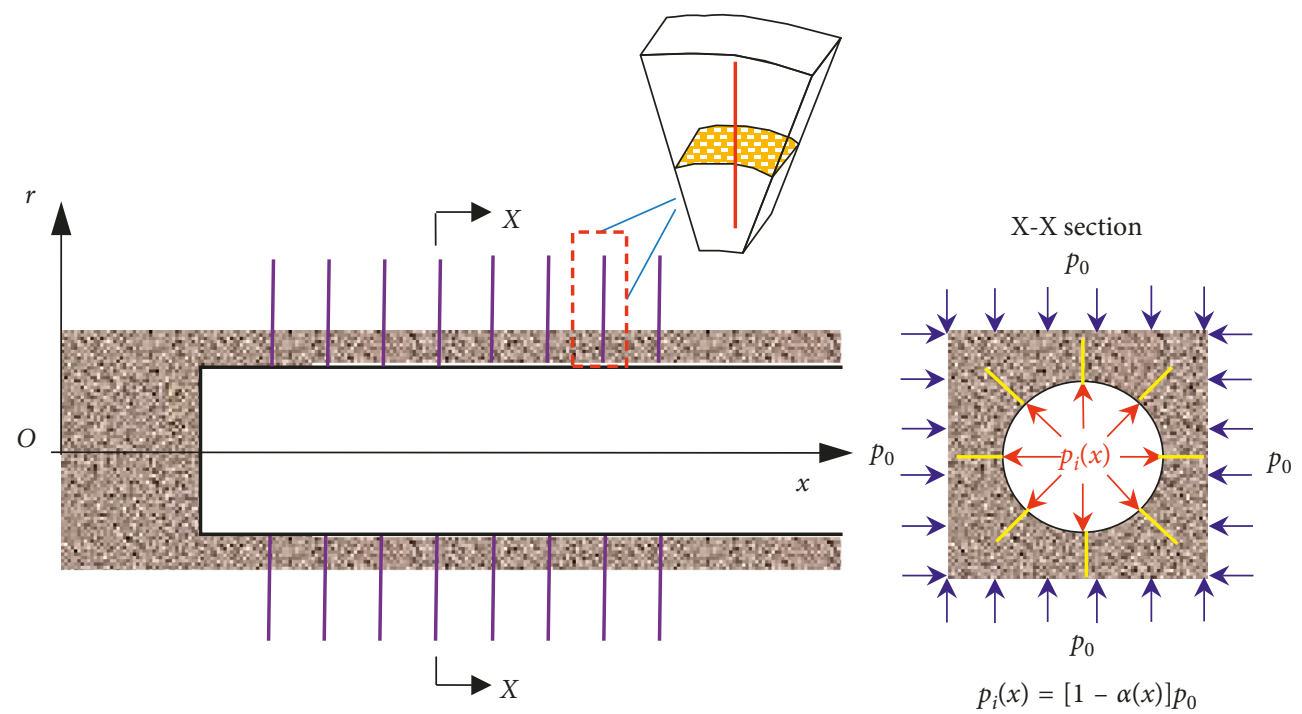

FIGURE 2: 2D semianalysis model for the full-face anchorage of the weakly cemented soft rock roadway.

problem can be converted to a plane axisymmetric problem. In this case, the response of the surrounding rock and stress is only related to the radial position. After installing the bolt in roadway, the mechanical response and boundary conditions of surrounding rock in the affected area of bolt will be changed. Therefore, we can divide the rock mass into the anchorage zone $\Omega_{1}$ and the nonanchorage zone $\Omega_{2}$ according to the support distribution, as shown in Figure 3. In the diagram, $p_{\alpha}$ is the virtual internal support pressure of the roadway, $\sigma_{\mathrm{c}}^{\mathrm{r}}$ is the radial stress on the interface between the anchorage zone and nonanchorage zone, and $\sigma_{0}$ is the initial stress. The normalized dimensionless length $\kappa=R / d$ is used to describe the radial position, and $\kappa$ should satisfy that $0 \leq \kappa \leq 1$, where, $d$ is the distance from the center of the roadway to any position in the radial direction. Obviously, when $\kappa=1$, it is the roadway inner wall. When $\kappa=\kappa_{\mathrm{c}}$, it is the anchorage end of the bolt; when $\kappa \longrightarrow 0$, it is the initial stress zone.

When $\alpha \leq \alpha^{*}$, which represents no rock bolts, the mechanical response of the surrounding rock has been given by Lame, which is the solution of the axisymmetric problem of thick wall cylinder. When $\alpha=\alpha^{*}$, the initial state of the installed bolt is as follows: the support pressure of the inner wall of the roadway is $p^{*}$, the radial stress of the contact surface between the anchorage area and the nonanchorage area is $\sigma_{\mathrm{r}}^{\mathrm{c} 0}$, and the initial stress is $\sigma_{0}$. Due to the reinforcement of the bolt, the stress state of the surrounding rock in the anchorage zone will be changed, and the boundary stress of the anchorage zone is changed accordingly. So, the boundary condition is changed as follows: the support pressure variation of the roadway inner wall is $\Delta p=p_{\alpha}-p^{*}$, and the variation of the radial stress of the contact surface between the anchorage area and the nonanchorage area is $\Delta \sigma_{\mathrm{r}}^{\mathrm{c}}=\sigma_{\mathrm{r}}^{\mathrm{c}}-\sigma_{\mathrm{r}}^{\mathrm{c} 0}$, and the variation of the initial stress is 0 . For this reason, the total response of the analysis model in Figure 3 can be decomposed into the sum of the initial state response and the incremental response by

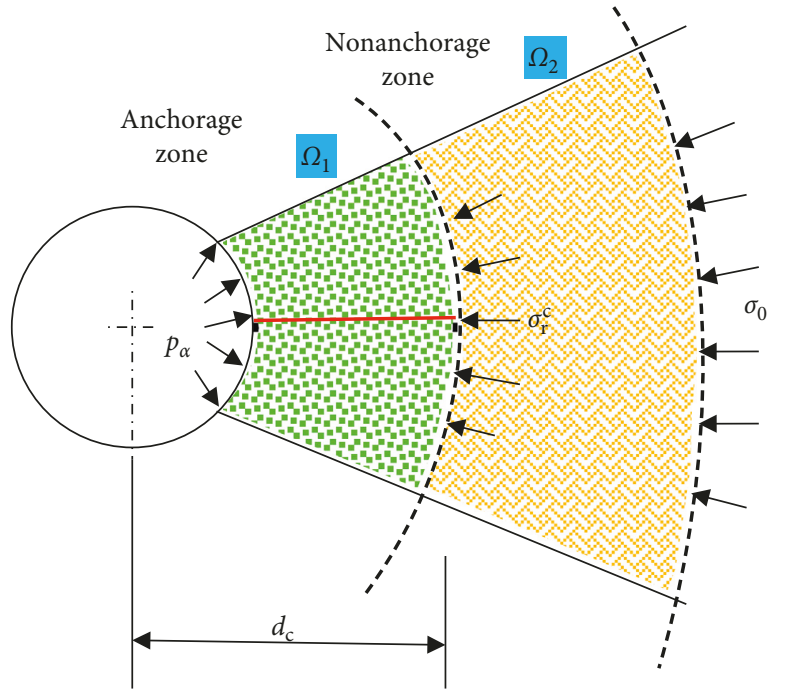

FIGURE 3: Analysis model of anchorage roadway.

the principle of superposition. The decomposition model is shown in Figure 4.

3.2. Analytic Solution of $2 D$ Semimodel of Full-Face Anchorage. We have deducted the two decomposition models in Figure 4 based on elastic theory and superposition principle in our former paper [30]. Further, we have established an analytical model of full-face anchorage roadway in hydrostatic pressure state. The obtained analytical solutions are as follows.

3.2.1. Solutions of Anchorage Zone. Radial stress in anchorage zone is

$$
\sigma_{\mathrm{r}}^{\Omega_{1}}=\left(1-\kappa^{2}\right) p_{0}+\kappa^{2} p^{*}+\frac{2 G \xi}{R} \kappa \Delta u_{\mathrm{r}}^{\Omega_{1}}-\frac{2 G(1+\xi)}{R} \kappa^{2} \Delta \dot{u}_{\mathrm{r}}^{\Omega_{1}} .
$$




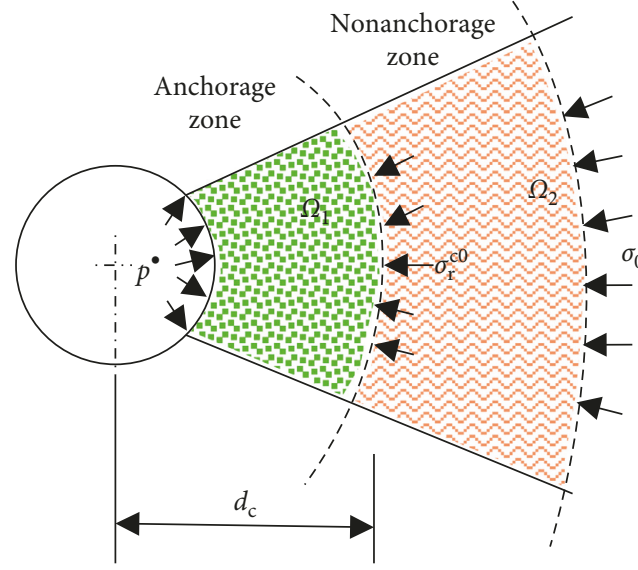

(a)

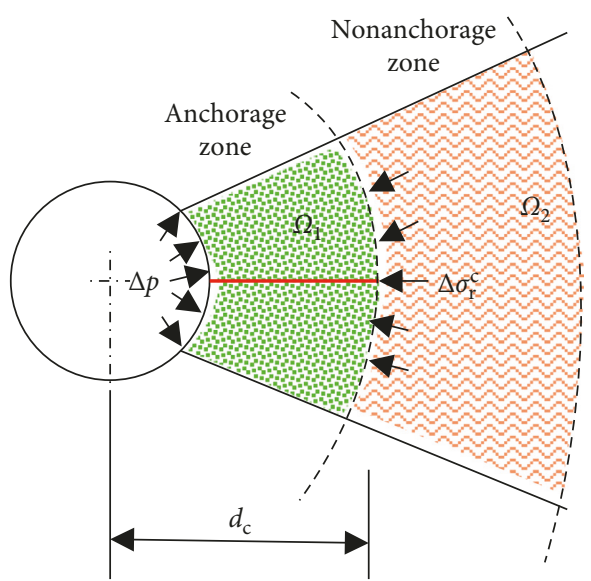

(b)

FIgURE 4: Decomposition for analysis model of anchorage roadway. (a) Initial state model. (b) Incremental model.

Tangential stress in anchorage zone is

$$
\sigma_{\theta}^{\Omega_{1}}=\left(1+\kappa^{2}\right) p_{0}-\kappa^{2} p^{*}+\frac{2 G(1+\xi)}{R} \kappa \Delta u_{\mathrm{r}}^{\Omega_{1}}-\frac{2 G \xi}{R} \kappa^{2} \Delta \dot{u}_{\mathrm{r}}^{\Omega_{1}}
$$

And the radial displacement in anchorage zone is

$$
u_{\mathrm{r}}^{\Omega_{1}}=\frac{R\left(p_{0}-p^{*}\right)}{2 G} \kappa+\Delta u_{\mathrm{r}}^{\Omega_{1}}
$$

3.2.2. Solutions of Nonanchorage Zone. Radial stress in the nonanchorage zone is

$$
\sigma_{\mathrm{r}}^{\Omega_{2}}=\frac{\left(K_{0} \kappa_{\mathrm{c}}^{2}-K_{0}+K_{1}\right) \sigma_{0}+K_{2} p^{*}+K_{3} \sigma_{T}+K_{4} p_{\alpha}}{K_{0} \kappa_{\mathrm{c}}^{2}} \kappa^{2} .
$$

Tangential stress in the nonanchorage zone is

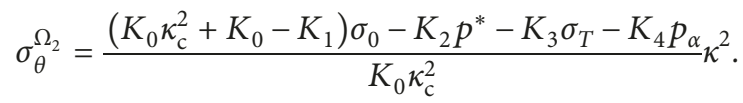

And the radial displacement in the nonanchorage zone is

$$
u_{\mathrm{r}}^{\Omega_{2}}=\frac{R}{2 G} \frac{\left(K_{0}-K_{1}\right) \sigma_{0}-K_{2} p^{*}-K_{3} \sigma_{T}-K_{4} p_{\alpha}}{K_{0} \kappa_{\mathrm{c}}^{2}} .
$$

According to Equations (2) and (3), $\Delta u_{\mathrm{r}}^{\Omega_{1}}$ and $\Delta \dot{u}_{\mathrm{r}}^{\Omega_{1}}$ is the radial displacement and its first derivative of the incremental model. According to Equations (5)-(7), $\sigma_{\mathrm{T}}$ is the bolt prestress. The specific expressions of $\Delta u_{\mathrm{r}}^{\Omega_{1}}$ and $\Delta \dot{u}_{\mathrm{r}}^{\Omega_{1}}$ in Equation (3) and $K_{0} \sim K_{6}$ in Equations (3) and (5)-(7) are detailed in our former paper [31], where $p^{*}=\left(1-\alpha^{*}\right) p_{0}$, and $\alpha^{*}$ is the stress release coefficient of the roadway with supporting, and $p_{\alpha} \leq p^{*}$. It can be seen that the rock bolt support has an influence on the stress and displacement of the anchorage zone and the nonanchorage zone. Different support time (different stress release) will lead to different anchoring effect. To reveal their mutual influence, we will discuss the results of the analytical solution in the fifth part of this paper.

\section{2D Seminumerical Simulation of Roadway with Full-Face Anchorage}

The calculation method for rock stress release simulation is the reverse stress release method, which is firstly proposed by Duncan and Dunlop [32], which only limited to the special case that the initial stress field is uniform. Later, the above idea was applied in the nonuniform stress field by the finite element method. Mana et al. used the element strain matrix to equalize the stress at the Gaussian point of the excavation unit to the node, and extracted the equivalent release load vector of the excavation unit, and then obtained the equivalent nodal force. The above method provides a good idea, but it is more complicated to realize. To tackle this problem, we will simulate the surrounding rock stress release by using virtual supporting force which is extracted from the reaction forces of section nodes. The core idea is to obtain the supporting force of the excavated body (before excavation) to the surrounding rock (the supporting force disappears with the removal of the excavation units), to rebuilt the supporting force and to control the rule of the stress release.

4.1. Numerical Model. A numerical analysis model is established by the finite element software ABAQUS. A uniform stress field is applied to the boundary of the model. The unit of the formation and the roadway adopt a fournode bilinear plane strain tetragonal unit CPE4R. The bolts use the TRUSS unit, which simulates the reinforcement effect by means of implanting into surrounding rock. This problem can simplify calculation by a $1 / 4$ model, but considering that the cost of computation is low, we use the complete model for simulation in order to show the analysis results more clearly. As shown in Figure 5, the rock formation is divided into 5588 units with 5621 nodes in total. The bolt is divided into two units by two-dimensional truss unit T2D2 with 400 units and 420 nodes in total. In order to correspond with the theoretical calculation model, this simulation model assumes rock and bolts as elastic bodies 


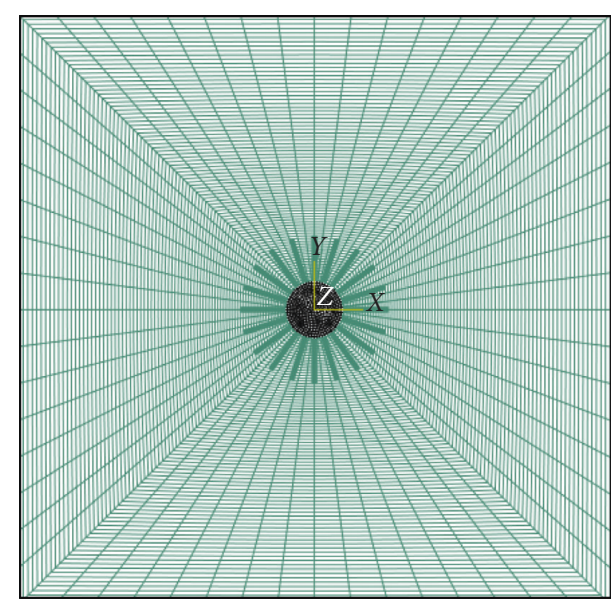

FIGURE 5: Finite element model of surrounding rock in anchorage roadway.

without plastic deformation. In the simulation, the reverse stress method is used to simulate the hierarchical release of the equivalent load, and the different construction process is analyzed.

The calculation parameters are listed in Table 1.

\subsection{Calculation Results}

4.2.1. Variation of the Virtual Internal Support Force with Different Stress Release Coefficients. By applying the node constraint, the node reaction force around the hole can be extracted, and then the node reaction force acted as the virtual internal support, which is applied to the excavation boundary to simulate stress release. Then, the virtual support force with different stress release coefficients can be obtained by MATLAB programming. Figure 6 shows the virtual internal support force in roadway excavation section and the variation rule of the virtual internal support force with different stress release coefficients, respectively. With the increase of the stress release coefficients, the virtual supporting force decreases continuously; thus, the two are negatively related. In the undisturbed area in front of the roadway face, the virtual internal support force is the initial stress. In the far distance behind the roadway face, the constraint disappears, so the virtual internal support force is 0 .

4.2.2. Stress Evolution of Surrounding Rock with Different Stress Release Coefficients. The stress release caused by excavation makes the stress of the rock mass within a certain range around the cavern constantly adjust until it reaches the new equilibrium state. Figures 7 and 8 show the stress evolution and evolution law of nonsupported surrounding rock with different stress release coefficients, respectively. With the increase of stress release coefficient, the radial stress of roadway inner wall decreases and the tangential stress increases continuously. When $\alpha=0$, it represents that the excavation section is not constrained by the roadway face and the radial stress $\sigma_{\theta}=2 \sigma_{\mathrm{r}}$ in roadway inner wall, which is
TABLE 1: Mechanical parameters of rock bolt and rock mass.

\begin{tabular}{lccc}
\hline \multicolumn{2}{c}{ Bolt } & \multicolumn{2}{c}{ Rock } \\
\hline Elastic modulus & $E_{\mathrm{m}}=200 \mathrm{GPa}$ & Elastic modulus & $E_{\mathrm{r}}=0.3 \mathrm{GPa}$ \\
Poisson's ratio & $v_{\mathrm{m}}=0.2$ & Poisson's ratio & $v_{\mathrm{r}}=0.25$ \\
Bolt length & $L=3 \mathrm{~m}$ & Roadway radius & $R=2 \mathrm{~m}$ \\
Bolt spacing & $n_{\mathrm{b}}=0.5 \mathrm{~m}$ & Initial stress & $\sigma_{0}=1 \mathrm{MPa}$ \\
Bolt diameter & $d=25 \mathrm{~mm}$ & - & - \\
\hline
\end{tabular}

consistent with the result of Lamy's solution. When $0<\alpha<1$, the above relation is not satisfied. However, regardless of the value of the stress release coefficient, in the elastic range, it is always satisfied that $\sigma_{\theta}+\sigma_{\mathrm{r}}=2 p$. The stress disturbance range of roadway excavation is about five times of the radius (5R), and the difference of stress release coefficient leads to obvious difference between radial stress and tangential stress distribution in $5 \mathrm{R}$ range. The tangential stress of surrounding rock is closely related to the damage degree, while the radial stress has the effect of confining pressure, which can restrain the failure of surrounding rock [31, 33]. Therefore, it is of great significance for the stability control of thick rock roadway to strengthen the surrounding rock and to improve the stress state of the surrounding rock.

4.2.3. Surrounding Rock Stress Distribution of Roadway with Full-Face Anchorage. In order to summarize the general rule, we extracted the stress variation data of anchoring surrounding rock with different stress release coefficients and then plotted the comparison diagram of stress changes before and after support. It can be found that the different supporting time (different stress release coefficients) can lead to different supporting effects. However, the overall trend is the almost same; that is, the bolt in the anchorage zone can effectively improve the radial stress of the surrounding rock, which is equivalent to the confining pressure acting on the surrounding rock, so as to improve the stability of the surrounding rock. At the same time, the bolt almost has no influence on the distribution of tangential stress with different stress release coefficients.

Figure 9 shows the stress variation of surrounding rock before and after support when $\alpha=0.6$. It can be seen that the radial stress of surrounding rock in anchorage zone has changed obviously compared with nonsupporting, and the shadow part shown in Figure 8 is the increment of the radial stress of surrounding rock. The radial stress of surrounding rock after support is obviously larger than that before blot support, and the most obvious change occurs in the range of $2.5 \mathrm{R}$. This indicates that the axial force of the bolt exerts an extrusion effect on the surrounding rock, thus improving the overall strength and self-bearing capacity of the surrounding rock. However, from the later analysis, this support effect cannot be evenly distributed along the length of the bolt, but decreases as the distance from the boundary of the roadway increases. Therefore, blindly increasing the anchorage length cannot effectively improve the stability of roadways.

4.2.4. Evolution of Rock Bolt Axial Force with Different Stress Release Coefficients. The distribution of axial force and the 


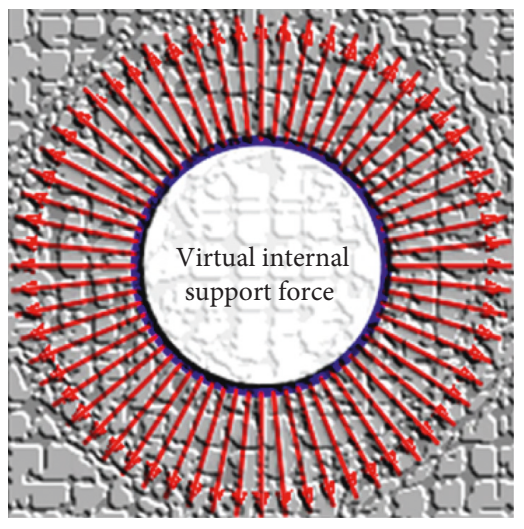

(a)

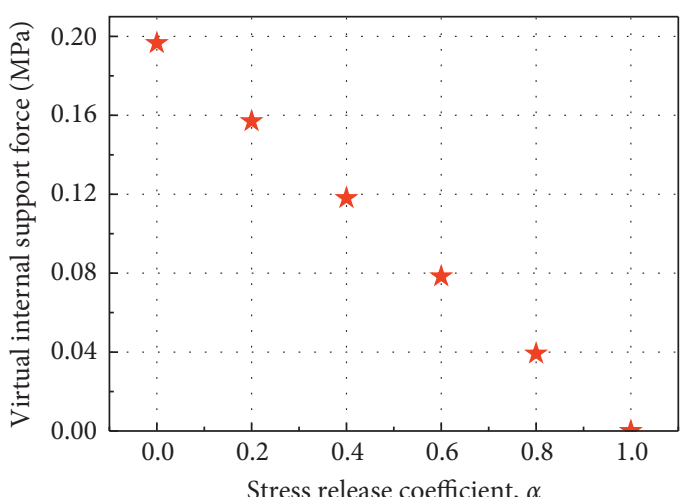

(b)

Figure 6: Virtual internal force diagram and different stress release values. (a) Virtual internal support force. (b) Virtual internal support force corresponding to different stress release coefficients.

variation of bolt force with different stress release coefficients are shown in Figures 10 and 11. Limited to the length of this paper, we only list the results of $\alpha=0.2,0.4,0.6$, and 0.8 , as shown in Figure 10. Hence, one can see that, the axial force distribution along the anchoring section is not uniform with different stress release coefficients. The axial force increases sharply with the increase of stress release coefficient. When $\alpha=0.8$, the maximum bolt axial force is nearly three times higher than that of $\alpha=0.2$. The bolt is mainly tensioned with larger force at the near-end. The maximum axial force does not appear at the end of the bolt, mainly because the surrounding rock is closed after support, and the rock deformation near the goaf face is restricted by the support. However, the distal rock mass still has a large deformation, and the farther the extension is, the greater the range of control deformation is, so the maximum axial stress of the bolt is gradually evolving into deep. Therefore, we should determine the reasonable stress release rate, give full play to the self-bearing capacity of surrounding rock, and play the optimal effect of supporting structure.

The bolt axial force evolves along the bolt length with different stress release coefficients is shown in Figure 11. With the increase of stress release coefficient, the deformation of surrounding rock increases correspondingly. Along the bolt length, the bolt axial force shows the trend of increasing first and then decreasing, and the bolt generates large tensile stress in near-end to limit the excessive deformation of the surrounding rock.

\section{Discussion on the Full-Face Anchorage Results}

5.1. Comparison between Theoretical Solution and Numerical Solution. The consistency of theoretical results with numerical results can be compared by adopting the same calculation parameters. In this paper, we randomly selected some parameters to be compared. Like $E$ in Table 1 is changed to $0.9 \mathrm{GPa}$ and $\alpha=0.4$, the comparison of the calculation results of surrounding rock stress and displacement is shown in Figures 12 and 13. The theoretical stress solution is calculated by using Equations (2), (3), (5), and (6), and the theoretical displacement solution is calculated by using Equations (4) and (7).

From Figure 12, it can be seen that the analytical solution of the surrounding rock stress in anchored roadway with a certain stress release coefficient basically agrees with that of the numerical solution. The maximum radial stress error is about $0.85 \%$, and the tangential stress error is $0.7 \%$. It shows that the analytical calculation highly corresponds to the results of numerical simulation. Due to the anchoring effect, the value of surrounding rock radial stress $\alpha_{\mathrm{r}}$ in the inner wall of the roadway is not equal to the virtual internal supporting force. As far from the excavation face, the radial stress $\alpha_{\mathrm{r}}$ gradually increases and the tangential stress $\sigma_{\theta}$ gradually decreases. Finally, the stress will approach the initial stress in the position about $5 \mathrm{R}$ away from the center of the roadway, while the tangential stress in roadway inner wall is higher than the initial stress.

Figure 13 is the theoretical solution and simulation solution of the radial displacement of surrounding rock when $\alpha=0.4$. Both the solutions consider the stress release, so the radial displacement of the surrounding rock is generated by the joint action of the initial stress and the virtual support force. The results show that the trend of the radial displacement obtained by numerical simulation is basically the same as that of the analytical value. However, due to the accuracy of numerical calculation, such as mesh partition and virtual support force extraction, there is some error between the simulation result and the analytical result, and the maximum error is about $1.82 \mathrm{~mm}$.

By comprehensive analysis and comparison, the surrounding rock stress and the radial displacement obtained from the theoretical analysis with specific stress release coefficient has good consistency with the numerical simulation results, indicating the reliability of the analytical model.

\subsection{Influence of Surrounding Rock Stiffness on Anchorage} Effect. To understand the influence of surrounding rock stiffness on anchorage effect, we analyze the radial stress distribution of surrounding rock under four kinds of stress 


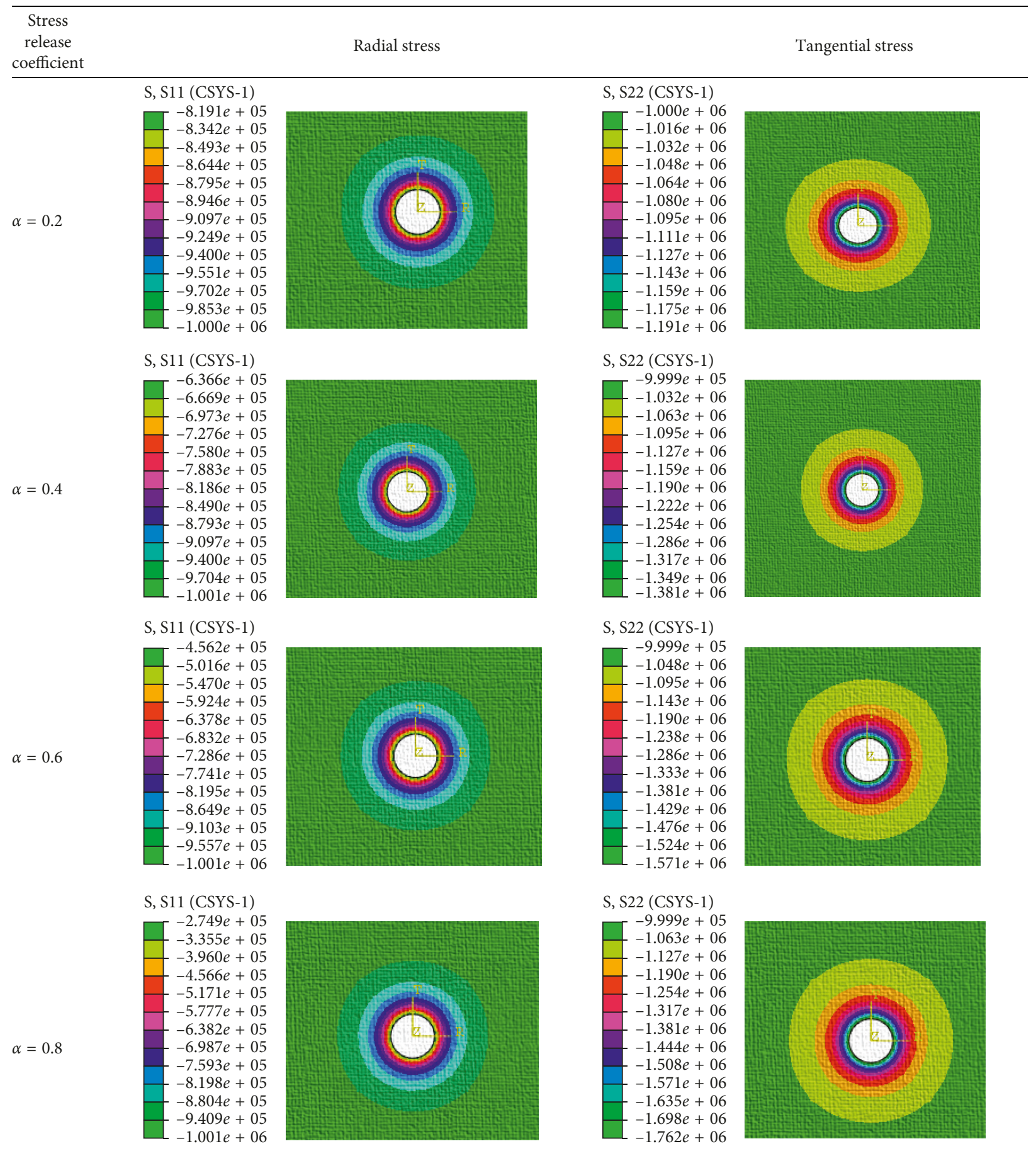

FIgURE 7: Contours of stress distribution of surrounding rock with different stress release coefficients.

release coefficient $(\alpha=0.2,0.4,0.6$, and 0.8$)$ and six kinds of surrounding rock stiffness $(E=0.1 \mathrm{GPa}, 0.5 \mathrm{GPa}, 0.7 \mathrm{GPa}$, $0.9 \mathrm{GPa}, 1.5 \mathrm{GPa}$, and $2.5 \mathrm{GPa}$ ) with the numerical model boundary conditions and supporting material parameters unchanged, and the results are shown in Figure 14. In anchorage zone, the stress distribution of surrounding rock is greatly affected by the stress release coefficient and surrounding rock stiffness. Under the same stress release coefficient, the radial stress shows the same change rule when the surrounding rock stiffness is taken $0.5 \mathrm{GPa}, 0.7 \mathrm{GPa}$, $0.9 \mathrm{GPa}, 1.5 \mathrm{GPa}$, and $2.5 \mathrm{Gpa}$, respectively. In the anchorage zone, with the increase of surrounding rock stiffness, the radial stress decreases continuously. Under the same surrounding rock stiffness, the larger the stress release coefficient, the smaller the radial stress in anchorage zone. It indicates that the stress change of bolt support to the soft rock is more significant than that of hard rock. In addition, with different stress release coefficients, the radial stress 


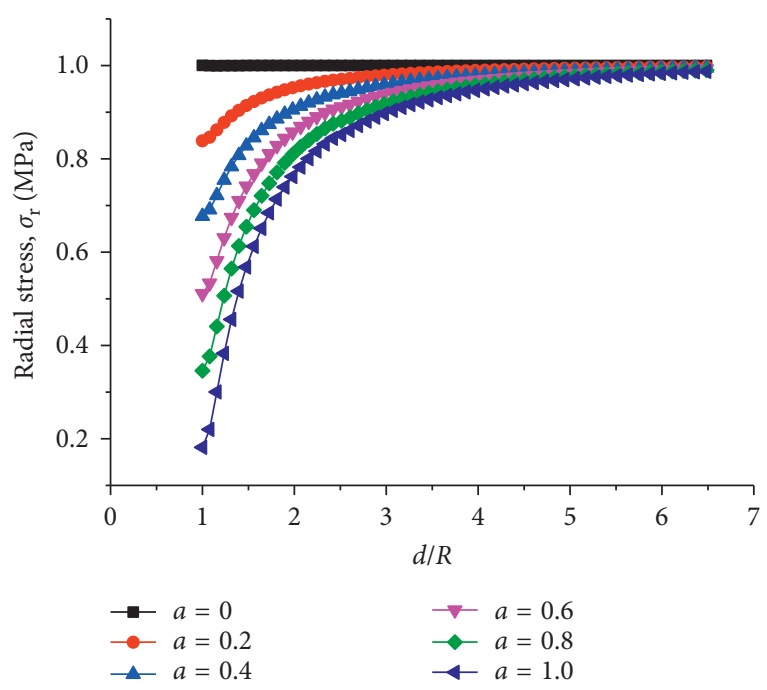

(a)

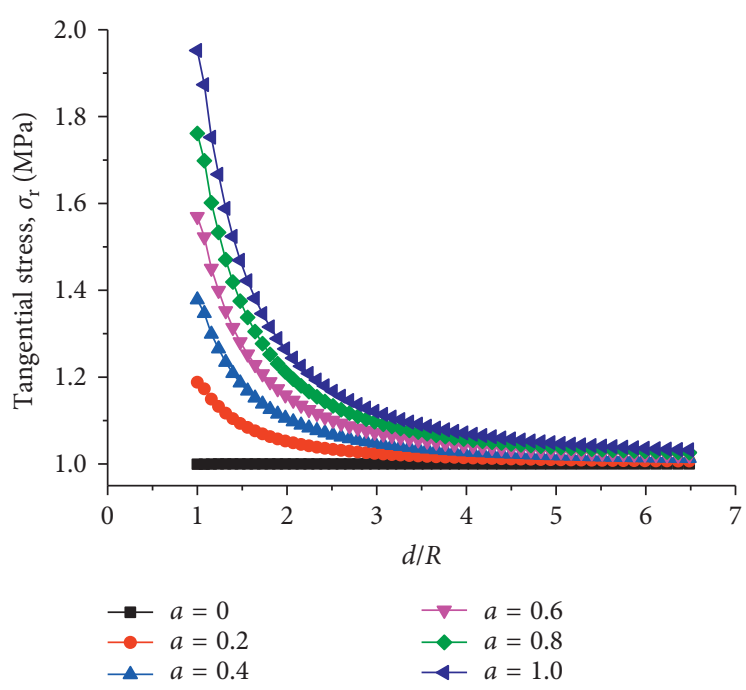

(b)

FIGURE 8: Effect of full-face anchorage on the stress distribution of surrounding rock with different stress release coefficients. (a) Radial stress. (b) Tangential stress.

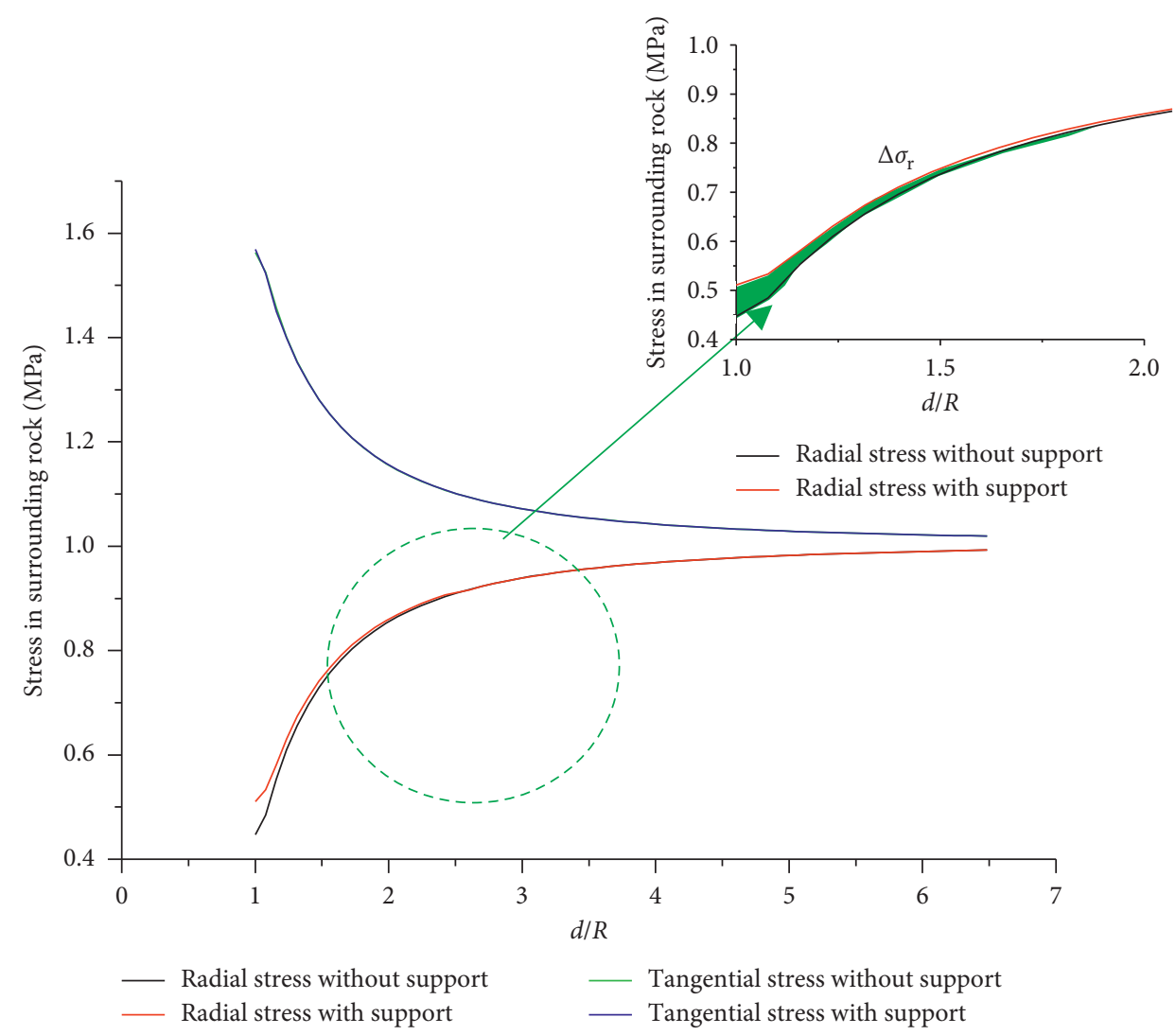

Figure 9: Variation of surrounding rock stress before and after support $(\alpha=0.6)$.

distribution shows quite different changes compared with other stiffness when $E=0.1 \mathrm{GPa}$. From the results of the four conditions, the radial stress of the surrounding rock shows the trend of increasing first and then decreasing. At the end of the anchorage zone, the curve of the radial stress of surrounding rock coincides with other stiffness curves. In the nonanchorage zone, there is no difference between the radial stress distributions of surrounding rock with different stiffness with the same stress release coefficient, which is completely consistent with the theoretical solution. When $E=0.1 \mathrm{GPa}$, the abnormal stress distribution is caused by the excessive distortion of the grid deformation. 


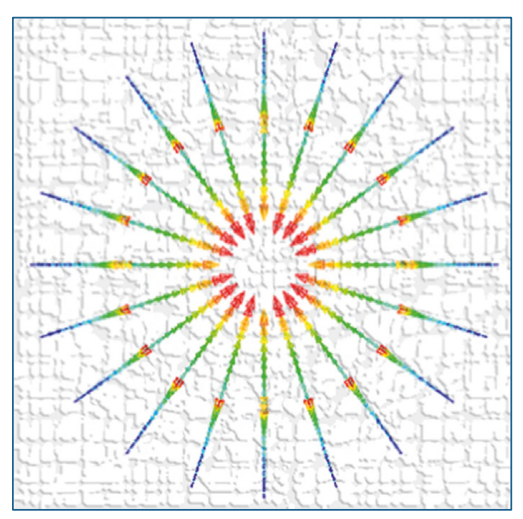

(a)

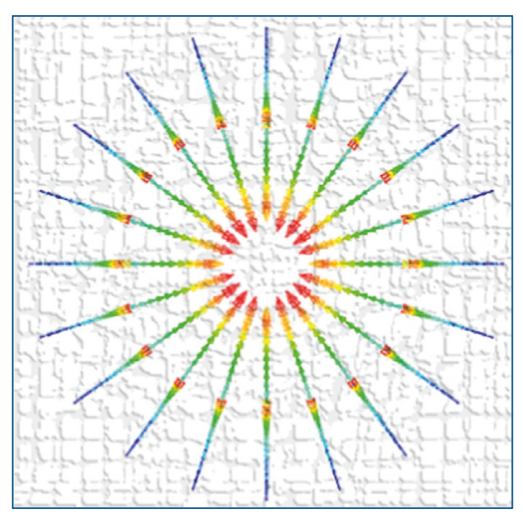

(c)

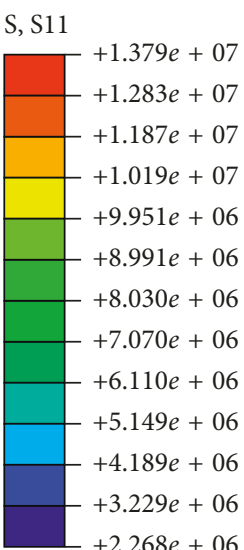

$+2.268 e+06$

S, S11

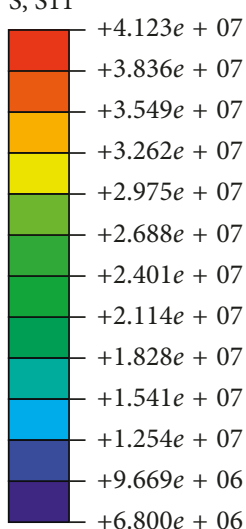

$+6.800 e+06$

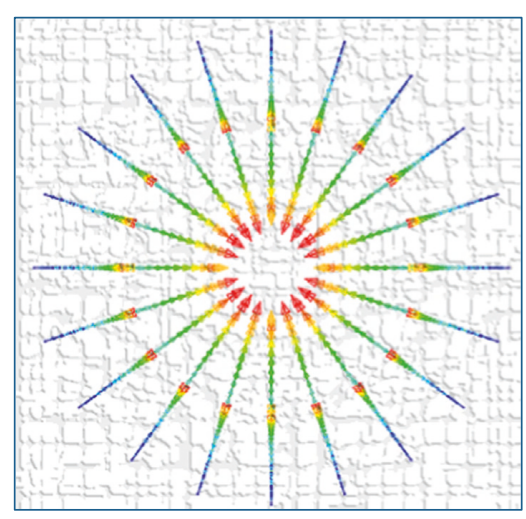

(b)

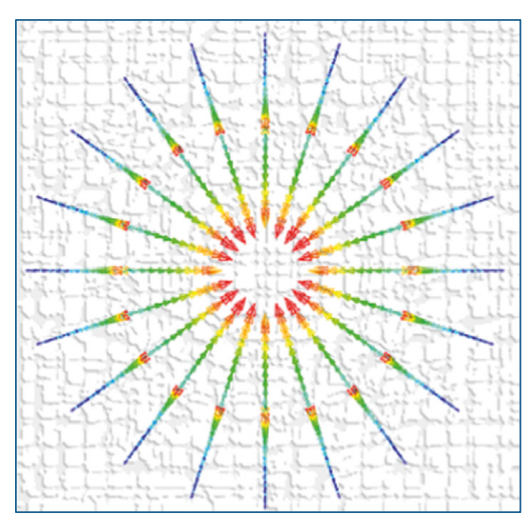

(d)

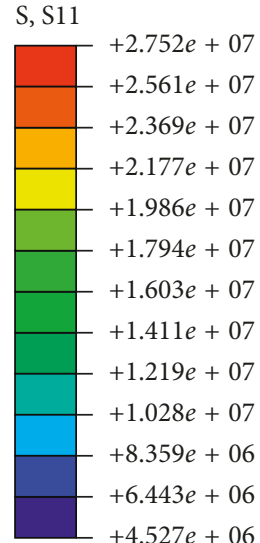

S, S11

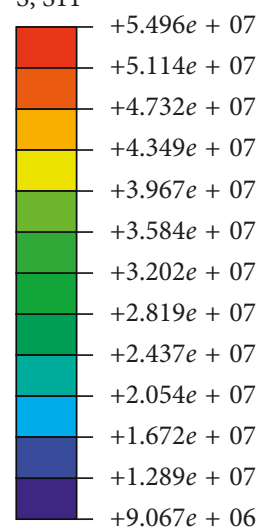

$+9.067 e+06$

Figure 10: Axial force distribution of bolt with different stress release coefficients. (a) $\alpha=0.2$, (b) $\alpha=0.4$, (c) $\alpha=0.6$, and (d) $\alpha=0.8$.

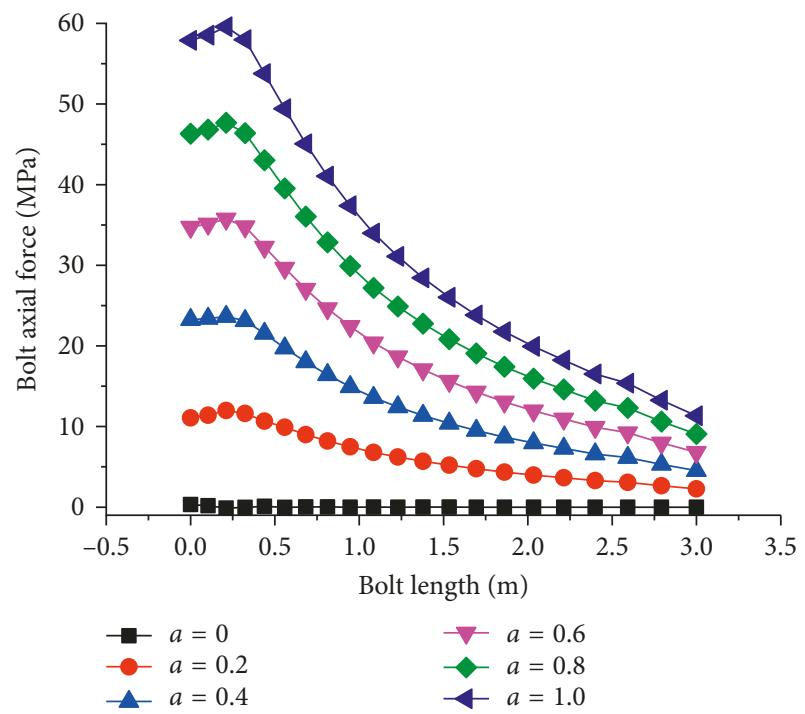

FIGURE 11: Evolution of bolt axial force with different stress release coefficients.

In order to further explain the influence of surrounding rock stiffness on the stress distribution of the supporting surrounding rock under certain degree of stress release,

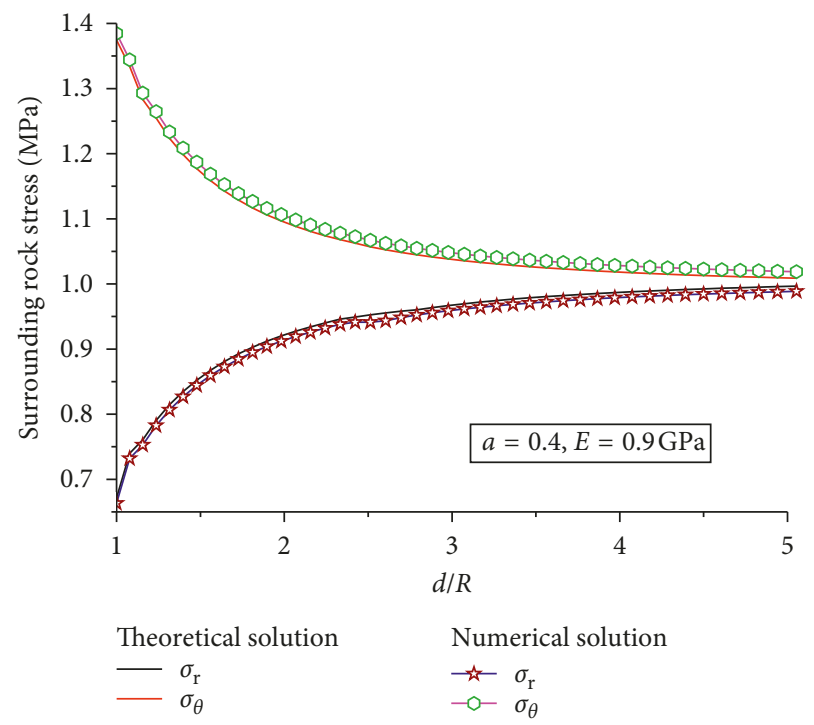

FIGURE 12: Comparison of surrounding rock stress when $\alpha=0.4$.

Figure 14 gives the stress contour cloud map of supporting surrounding rock with $\alpha=0.4$. It can be seen that the peak value of the tangential stress of the surrounding rock basically remains unchanged with the increase of the 


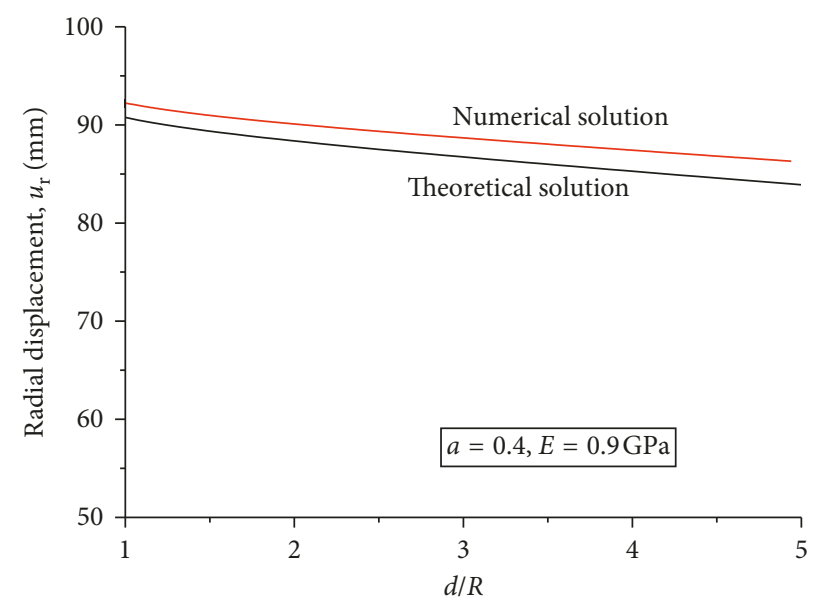

FIGURE 13: Radial displacement of surrounding rock when $\alpha=0.4$.

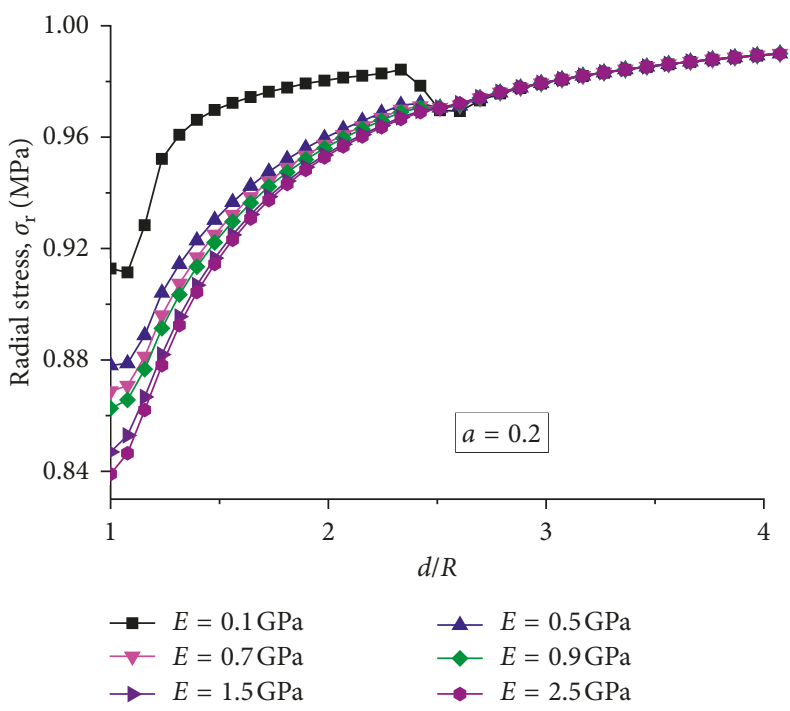

(a)

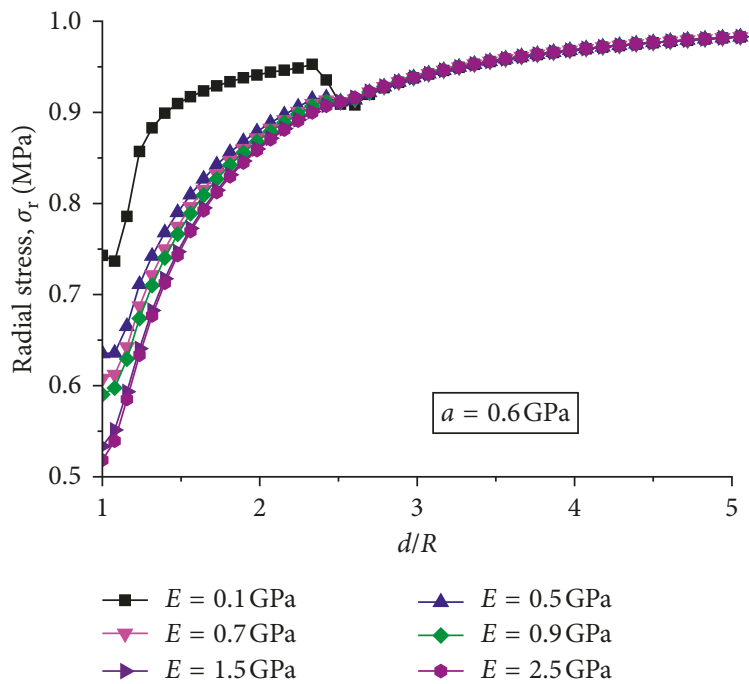

(c)

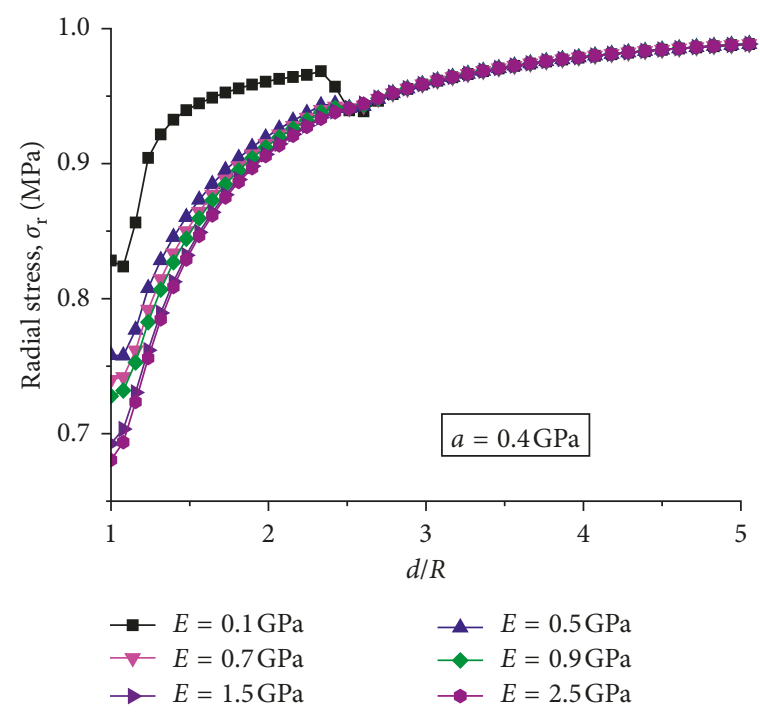

(b)

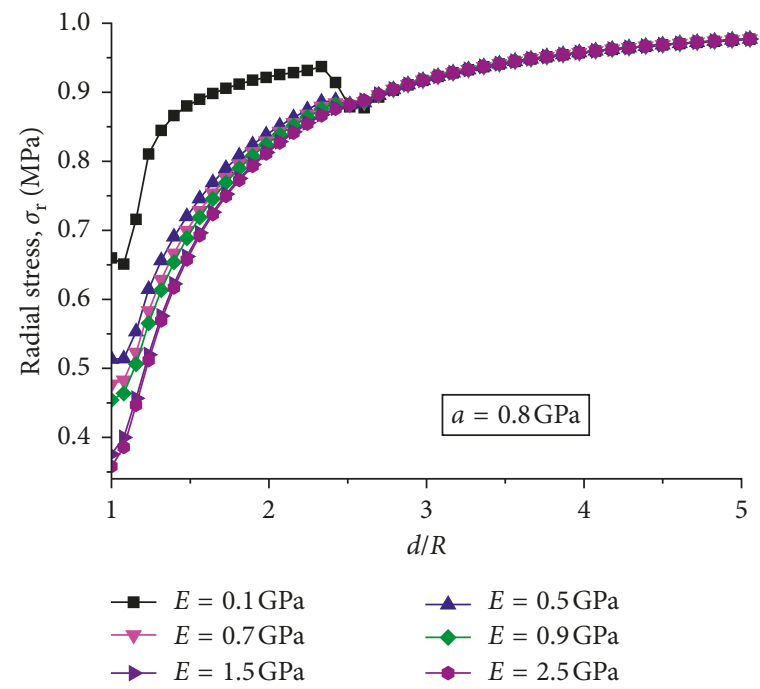

(d)

Figure 14: Stress distribution with different surrounding rock stiffness. 


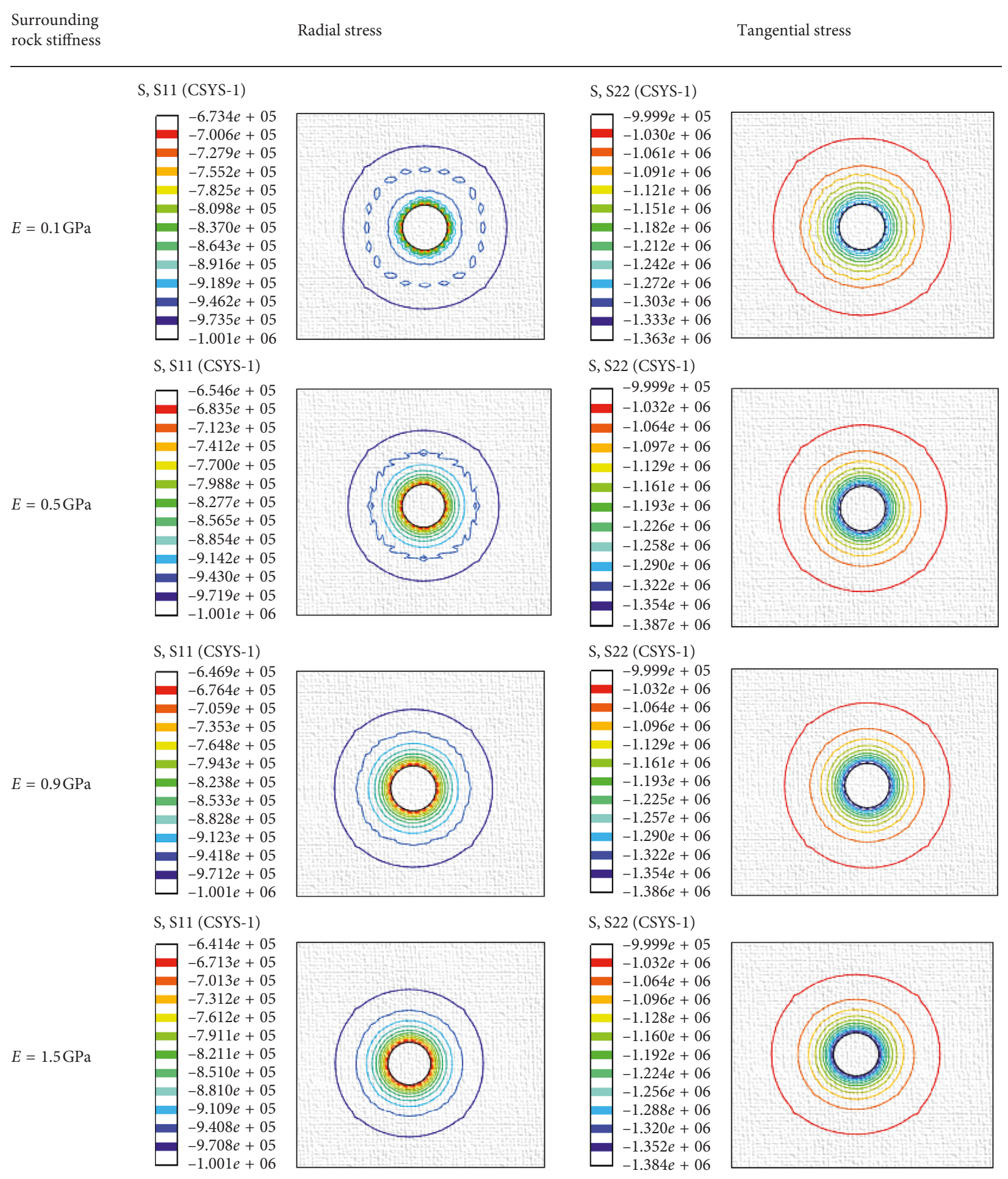

Figure 15: Distribution of stress with different surrounding rock stiffness $(\alpha=0.4)$.

surrounding rock stiffness. It indicated that the surrounding rock stiffness has no influence on the tangential stress distribution. However, the stiffness has a great influence on the radial stress distribution. When $E=0.1 \mathrm{GPa}$, the radial stress in anchorage zone boundary does not form a circular contour line but shows a spot distribution. Moreover, the concentric circles are less distributed in the anchorage zone.
When $E=0.5 \mathrm{GPa}$, the discrete points are connected to be a contour line with circular dentate distribution. With the increase of the surrounding rock stiffness, the radial stress in anchorage zone boundary gradually forms a contour circle. This distribution rule also illustrates the abnormality of the radial stress distribution of the low-stiffness surrounding rock, as shown in Figure 15. 
Under the assumption that the surrounding rock is an elastic medium, the influence of bolt length on stress distribution and displacement of surrounding rock will show the same change rule under different stress release coefficients and surrounding rock stiffness.

5.3. Variation Law and Influencing Factors of Bolt Axial Force. Assuming the yield limit of the bolt is $\sigma_{\mathrm{s}}=700 \mathrm{MPa}$, taking the safety coefficient as $n=1.5$, so the maximum axial force can be described as

$$
\left[\sigma_{n \max }\right]=\frac{\sigma_{\mathrm{s}}}{n}=467 \mathrm{MPa} .
$$

That is, the maximum stress of the bolt is $467 \mathrm{MPa}$ with certain prestress and material parameter. In the theoretical model, the established calculation equation of the bolt axial force is

$$
\sigma_{\mathrm{N}}=-E_{\mathrm{m}} \frac{\kappa^{2}}{R} \Delta \dot{u}_{\mathrm{r}}^{\Omega_{1}}+\sigma_{\mathrm{T}},
$$

where $E_{\mathrm{m}}$ is elastic modulus of the bolt, the value shown in Table 1 , and $\sigma_{\mathrm{T}}$ is the anchor prestress.

According to Equation (9), we plot the matching relationship between the bolt prestress, the stress levels, and the surrounding rock stiffness considering the bearing capacity of the bolt, as shown in Figure 16. The abscissa in the figure represents the elastic modulus of the surrounding rock and the ordinate represents the bolt prestress. In a certain degree of surrounding rock stiffness, let $\sigma_{n}=$ $467 \mathrm{MPa}, \kappa=1$ in Equation (9), we can obtain the maximum bolt prestress. So, we can also obtain a data point, further, by changing the surrounding rock stiffness and obtain other data points by analogy. Therefore, each data point in the figure represents the maximum prestress of bolt that can be applied to the surrounding rock under certain stiffness, which can ensure the safety of the bolt. Using the same method, the matching relationships of other parameters can also be obtained.

When $E_{\mathrm{r}} \leq 0.5 \mathrm{GPa}$, the limit value of prestress $\sigma_{\mathrm{T} \max }$ is more sensitive to the variation of $E_{\mathrm{r}}$ and the initial stress $\sigma_{0}$. When $\sigma_{0} \leq 0.9 \mathrm{MPa}, \sigma_{\mathrm{T} \max }$ decreases with the increase of the elastic modulus of surrounding rock. On the contrary, when $\sigma_{0}>0.9 \mathrm{MPa}$, the prestress limit $\sigma_{\mathrm{T} \max }$ increases with $E_{\mathrm{r}}$ increase. When $E_{\mathrm{r}}>0.5 \mathrm{GPa}, \sigma_{\mathrm{T} \max }$ basically remained unchanged, which is not sensitive to the change of $E_{\mathrm{r}} \& \sigma_{0}$. In addition, when $\sigma_{0}>1.2 \mathrm{MPa}, \sigma_{\mathrm{T} \max }$ appeared positive value, indicating the prestressing is compressive stress. It is suggested that the bolt can also reach the yield limit without applying prestress. Generally speaking, $\sigma_{\mathrm{T} \max }$ is more sensitive to the stiffness of soft rock. On the other hand, it also shows that the variation of the rock bolt axial force in soft rock is more obvious. The prestress loss of bolts in soft rock is more obvious than that in hard rock.

\section{Conclusions}

This paper conducts a systematic analysis on the interplay between stress release, rock bolt supporting and surrounding rock system of weakly cemented soft rock roadway with

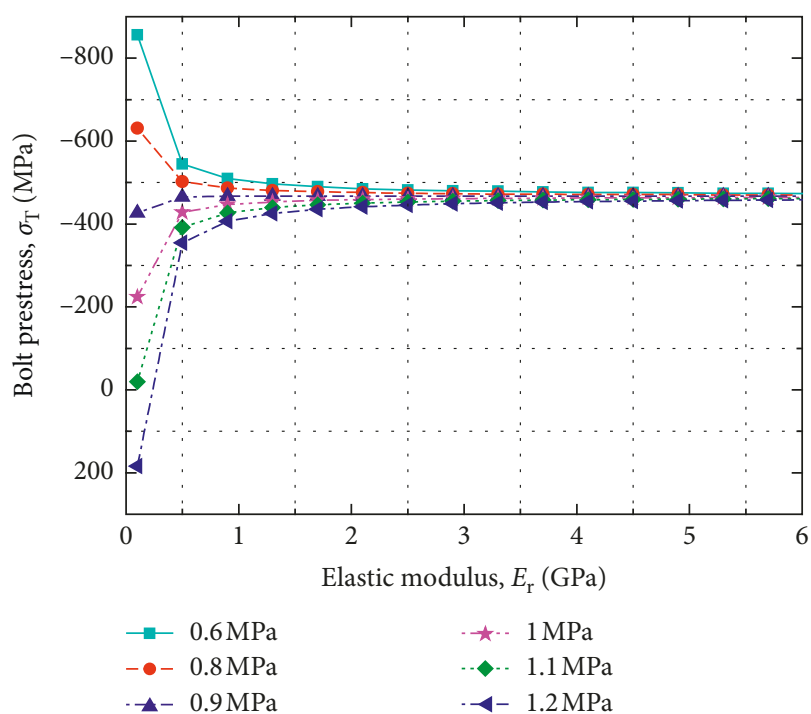

FIgURE 16: Matching relation between rock stiffness and bolt prestress considering the bearing capacity of rock bolt.

full-face anchorage. The influence of stress release, rock properties, and rock bolt prestress on the supporting effect is analyzed in detail based on theoretical analysis and numerical simulation. The main conclusions are as follows:

(1) The stress release of the surrounding rock can be effectively equivalent to the virtual internal support force of the excavation face in the longitudinal direction, which can effectively characterize the degree of stress release of the surrounding rock. The theoretical solution obtained by this method is consistent with the numerical simulation results, indicating that the model is reliable. In this sense, the proposed model can effectively reveal the mechanical response of the surrounding rock and the rock blot support system with different stress release coefficients.

(2) On one hand, with the increase of the stress release degree, the radial stress of surrounding rock decreases obviously, while the tangential stress increases gradually. The anchoring effect of the bolt is manifested in the improvement of the radial stress in the anchorage zone, which has little effect on the tangential stress. It indicates that the axial force of the bolt exerts an extrusion effect on the surrounding rock, thus changing the bearing structure. On the other hand, with the increase of the stress release coefficient, the axial force of bolt increases accordingly, the bolt axial force increases first and then decreases along the bolt length, resulting in a large tensile stress at the near-end of the bolt, which is not in the inner wall of the roadway. In addition, the maximum bolt prestress, the initial stress, and the parameters of the surrounding rock show some typical matching relations. While the limit value of the bolt prestress is more sensitive to the stiffness of soft rock, the prestress loss of the bolt in soft rock is more obvious than that in hard rock. 
(3) Under the same stress release coefficient, the radial stress in the anchorage area decreases with the increase of the stiffness of the surrounding rock. Under the same surrounding rock stiffness, the larger the stress release coefficient, the smaller the radial stress in the anchorage zone. It indicates that the stress change of bolt support to soft rock is more significant than that of hard rock.

(4) In order to obtain the closed solution of the anchorage model, in this paper, we assume that the rock mass is in the elastic medium without considering the plastic damage of the surrounding rock, which is different from the actual situation. Even so, with the aid of this model, the interaction mechanism of full-face anchorage, stress release, and the bolt surrounding rock system can be illustrated, which is beneficial for further consideration of the strain softening behavior in soft surrounding rocks. Furthermore, the interaction mechanism between the bolt and the surrounding rock in the plastic zone will become a study emphasis in our further research.

\section{Data Availability}

The calculation data used to support the findings of this study are included within the article.

\section{Conflicts of Interest}

The authors have no conflicts of interest.

\section{Acknowledgments}

This study was supported by the National Natural Science Foundation of China (Nos. 51774196 and 41472280), China Postdoctoral Science Foundation (No. 2016M592221), Major Program of Shandong Province (ZR2018ZC0740), and Natural Science Foundation and SDUST Young Teachers Teaching Talent Training Plan (No. BJRC20160501).

\section{References}

[1] Z. Zhao, Q. Ma, S. Chen, H. Ma, and X. Gao, "Prediction model of failure zone in roadway sidewall considering the lithologic effect of rock formation," Mathematical Problems in Engineering, vol. 2018, Article ID 9627564, 12 pages, 2018.

[2] Z. Zhao, W. Wang, L. Wang, and C. Dai, "Compression-shear strength criterion of coal-rock combination model considering interface effect," Tunnelling and Underground Space Technology, vol. 47, pp. 193-199, 2015.

[3] Z. H. Zhao, Q. Ma, Y. L. Tan, and X. J. Gao, "Load transfer mechanism and reinforcement effect of segmentally yieldable anchorage in weakly consolidated soft rock," Simulation Transactions of the Society for Modeling and Simulation International, vol. 4, article 003754971877028, 2018.

[4] H. Kang, J. Wang, and L. Jian, "Case studies of rock bolting in coal mine roadways," Chinese Journal of Rock Mechanics and Engineering, vol. 29, no. 4, pp. 649-664, 2010.

[5] Z. Zhao, W. Wang, and L. Wang, "Theoretical analysis of a new segmented anchoring style in weakly cemented soft surrounding rock," International Journal of Mining Science and Technology, vol. 26, no. 3, pp. 401-407, 2016.

[6] C. O. Aksoy and T. Onargan, "The role of umbrella arch and face bolt as deformation preventing support system in preventing building damages," Tunnelling and Underground Space Technology, vol. 25, no. 5, pp. 553-559, 2010.

[7] A. Bobet and H. H. Einstein, "Roadway reinforcement with rockbolts," Tunnelling and Underground Space Technology, vol. 26, no. 1, pp. 100-123, 2011.

[8] A. Fahimifar and M. Ranjbarnia, "Analytical approach for the design of active grouted rockbolts in roadway stability based on convergence-confinement method," Tunnelling and Underground Space Technology, vol. 24, no. 4, pp. 363-375, 2009.

[9] R. K. Goel, A. Swarup, and P. R. Sheorey, "Bolt length requirement in underground openings," International Journal of Rock Mechanics and Mining Sciences, vol. 44, no. 5, pp. 802-811, 2007.

[10] Y. L. Tan, F. H. Yu, J. G. Ning, and T. B. Zhao, "Design and construction of entry retaining wall along a gob side under hard roof stratum," International Journal of Rock Mechanics and Mining Sciences, vol. 77, pp. 115-121, 2015.

[11] L. R. Alejano, A. Rodríguez-Dono, and M. Veiga, "Plastic radii and longitudinal deformation profiles of roadways excavated in strain-softening rock masses," Tunnelling and Underground Space Technology, vol. 30, no. 3, pp. 169-182, 2012.

[12] H. Basarir, M. Genis, and A. Ozarslan, "The analysis of radial displacements occurring near the face of a circular opening in weak rock mass," International Journal of Rock Mechanics and Mining Sciences, vol. 47, no. 5, pp. 771-783, 2010.

[13] S. J. Chen, X. Qu, D. W. Yin, X. Q. Liu, H. F. Ma, and H. Y. Wang, "Investigation lateral deformation and failure characteristics of strip coal pillar in deep mining," Geomechanics and Engineering, vol. 14, no. 5, pp. 421-428, 2018.

[14] M. Karakus, "Appraising the methods accounting for 3D roadwayling effects in 2D plane strain FE analysis," Tunnelling and Underground Space Technology, vol. 22, no. 1, pp. 47-56, 2007.

[15] M. F. Lei, L. M. Peng, and C. H. Shi, "Model test to investigate the failure mechanisms and lining stress characteristics of shallow buried roadways under unsymmetrical loading," Tunnelling and Underground Space Technology, vol. 46, pp. 64-75, 2015.

[16] S. X. Yang, H. Li, M. Z. Bai, and Z. Y. Xu, “The wall-rock's stress releasing regularity arose by cavern excavation in the high stress condition," Journal of China Coal Society, vol. 35, no. 1, pp. 26-30, 2010.

[17] W. S. Zhu, Q. B. Zhang, H. H. Zhu et al., "Large-scale geomechanical model testing of an underground cavern group," Canadian Geotechnical Journal, vol. 47, no. 9, pp. 935-946, 2010.

[18] Y. Liu, X. Zhang, L. I. Jiali, X. Yang, and S. O. Transportation, "Study of rock stress release rate in shallow-buried roadway based on displacement-back-analysis," Journal of Wuhan University of Technology, vol. 39, no. 6, pp. 1259-1262, 2015, in Chinese.

[19] G. Mollon, D. Dias, and A. H. Soubra, "Probabilistic analyses of roadwaying-induced ground movements," Acta Geotechnica, vol. 8, no. 2, pp. 181-199, 2013.

[20] T. Funatsu, H. Hoshino, H. Sawae, and H. Shimizu, "Numerical analysis to better understand the mechanism of the effects of ground supports and reinforcements on the stability of roadways using the distinct element method," Tunnelling 
and Underground Space Technology, vol. 23, no. 5, pp. 561573, 2008.

[21] B. Li, Y. Hong, B. Gao, T. Y. Qi, Z. Z. Wang, and J. M. Zhou, "Numerical parametric study on stability and deformation of roadway face reinforced with face bolts," Tunnelling and Underground Space Technology, vol. 47, pp. 73-80, 2015.

[22] S. Kielbassa and H. Duddeck, "Stress-strain fields at the roadwayling face-three-dimensional analysis for twodimensional technical approach," Rock Mechanics and Rock Engineering, vol. 24, no. 3, pp. 115-132, 1991.

[23] S. Maghous, D. Bernaud, and E. Couto, "Three-dimensional numerical simulation of rock deformation in bolt-supported roadways: a homogenization approach," Tunnelling and Underground Space Technology, vol. 31, no. 5, pp. 68-79, 2012.

[24] Y. Yang, J. Zheng, H. Lai, and X. Wu, "A revised method for calculating stress release ratio in roadway excavation," Chinese Journal of Rock Mechanics and Engineering, vol. 34, pp. 2251-2257, 2015.

[25] C. Zhang and K. Zeng, "Comparisons and applications of displacement release coefficients for a circular rock roadway subjected to isotropic geostresses," Chinese Journal of Rock Mechanics and Engineering, vol. 34, no. 3, pp. 498-510, 2015.

[26] N. A. Do, D. Dias, P. Oreste, and I. Djeran-Maigre, "2D numerical investigation of segmental roadway lining behavior," Tunnelling and Underground Space Technology, vol. 37, no. 6, pp. 115-127, 2013.

[27] T. Svoboda and D. Masin, "Comparison of displacement field predicted by $2 \mathrm{D}$ and $3 \mathrm{D}$ finite element modelling of shallow NATM roadways in clays," Geotechnik, vol. 34, no. 2, pp. 115-126, 2011.

[28] M. Panet and A. Guenot, "Analysis of convergence behind the face of a roadway," in Roadwayling, vol. 82, pp. 197-204, Institution of Mining and Metalluragy, London, UK, 1982.

[29] B. H. G. Brady and E. T. Brown, Rock Mechanics for Underground Mining, Springer, Berlin, Germany, 2006.

[30] Z. H. Zhao, W. M. Wang, Y. L. Tan, and L. H. Wang, "Quantitative model of full-face anchoring in thick soft rock roadway," Journal of China Coal Society, vol. 41, no. 7, pp. 1643-1650, 2016.

[31] G. Zhao, X. Zhang, X. Meng, and K. Wang, "Elasto-brittle damage analysis of roadway surrounding rock based on continuous damage theory," Chinese Journal of Underground Space and Engineering, vol. 12, no. 2, pp. 314-320, 2016.

[32] P. Dunlop and J. M. Duncan, "Development of failure around excavated slopes," Journal of the Soil Mechanics and Foundations Division, vol. 96, pp. 471-493, 1970.

[33] K. K. Panthi and B. Nilsen, "Uncertainty analysis of roadway squeezing for two roadway cases from nepal himalaya," International Journal of Rock Mechanics and Mining Sciences, vol. 44, no. 1, pp. 67-76, 2007. 


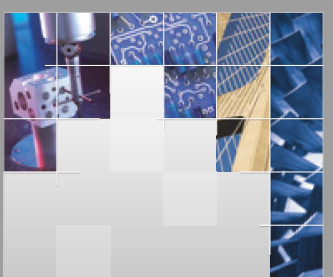

\section{Enfincering}
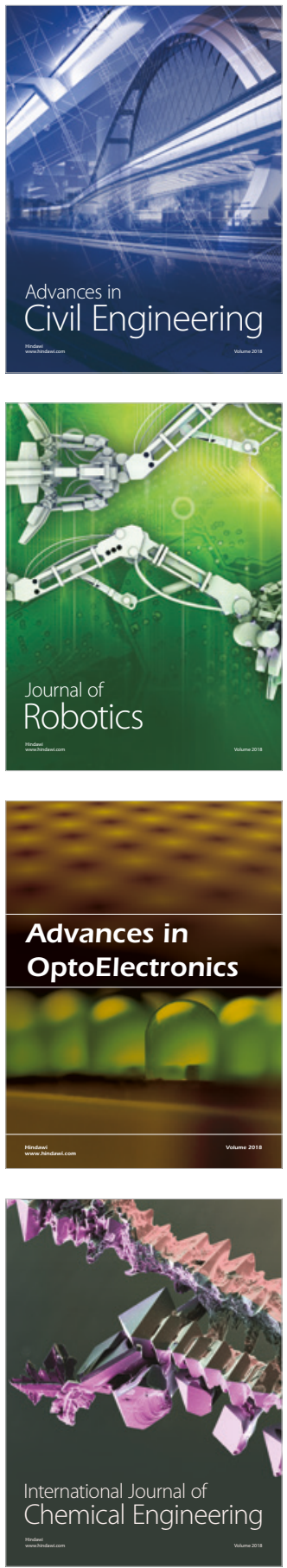

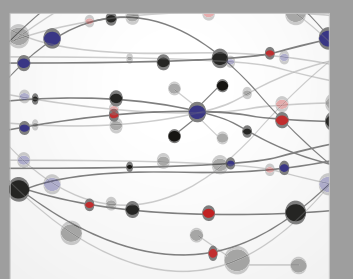

\section{Rotating \\ Machinery}

The Scientific World Journal

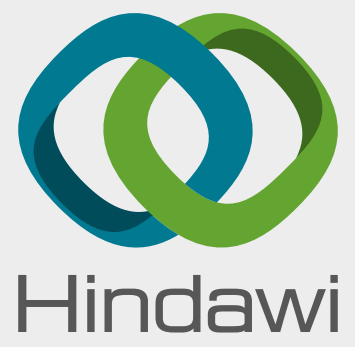

Submit your manuscripts at

www.hindawi.com
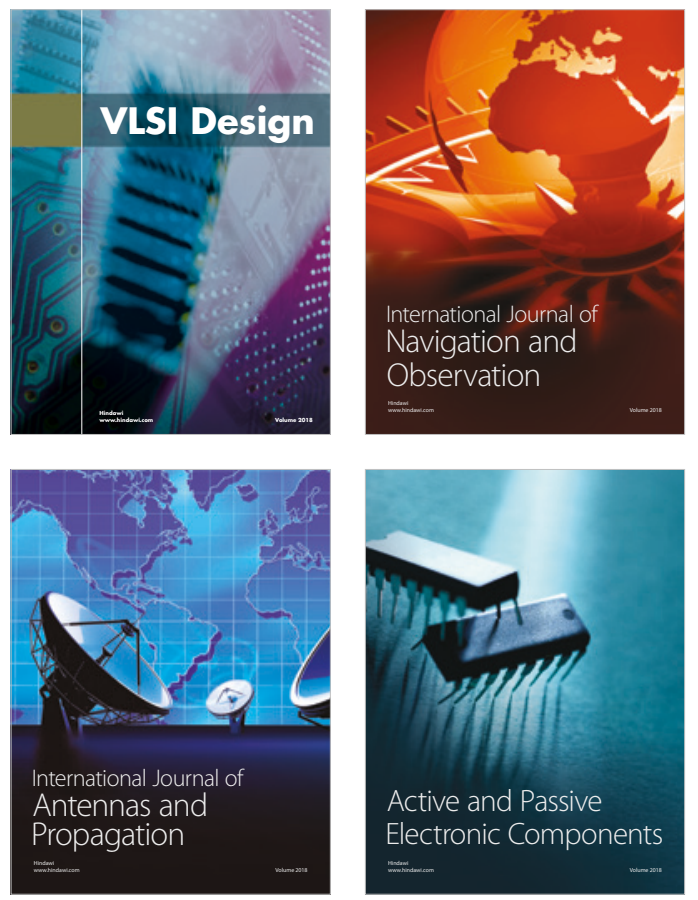
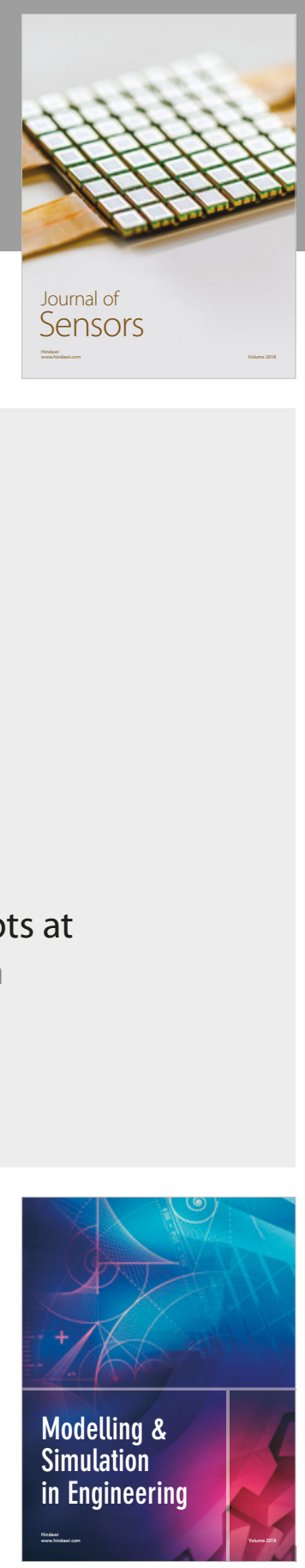

\section{Advances \\ Multimedia}
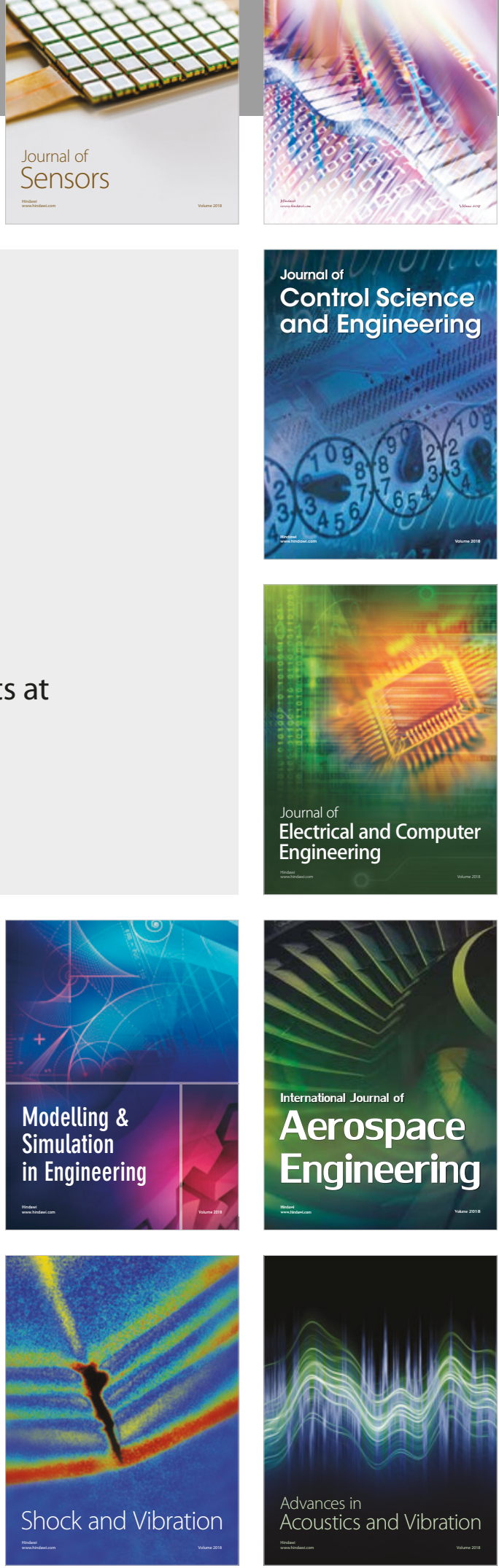